\title{
Uso y percepción del espacio público, una mirada desde la población: el caso de Cuenca, Ecuador
}

\author{
Use and perception of public space from the view of population: The case study of Cuenca, Ecuador
}

\section{Paula Camila Muñoz-Vanegas}

Universidad de Cuenca, Cuenca, Ecuador.

\section{María Augusta Quizhpe-Marín}

Universidad de Cuenca, Cuenca, Ecuador.

\section{Ximena Salazar-Guaman}

Universidad de Cuenca, Cuenca, Ecuador.

ximena.salazar@ucuenca.edu.ec

\section{Resumen}

La dinámica social es inherente a los espacios públicos, los cuales deben propiciar el encuentro e interacción de los diversos usuarios. A más de ello, es necesario disponer de información para el proyecto que supere las preconcepciones de diseño que generalmente tiene el proyectista. No obstante, consiste un reto captar con claridad las experiencias, opiniones y actividades que ejercen los usuarios en estos espacios. El objetivo de este artículo es plantear una metodología para el diagnóstico de espacios públicos que capte la dinámica cotidiana de la población, la percepción sobre los elementos que los constituyen, así como el rol que cumplen en el barrio y en el contexto de la ciudad. La propuesta metodológica se enmarca en una perspectiva sistémica que determina las distintas dimensiones que lo estructuran, los criterios de calidad y sus interrelaciones, empleando distintos instrumentos (observación, encuesta y entrevista). Como caso de estudio se trabaja en las Plazas EI Vergel y El Carbón, ubicadas en barrios históricos de Cuenca, Ecuador, obteniendo como resultado una caracterización integral, así como un conocimiento detallado de la percepción de la población y el uso del espacio de forma estructurada y organizada en base a la argumentación teórica. Tras la aplicación de la propuesta metodológica se ratifica la importancia de la participación de la población en las intervenciones, resultando en elementos comunes que pueden ser generalizados y a su vez, en particularidades de cada espacio.

Palabras clave: espacios públicos, participación ciudadana, percepción del espacio público, proyectos urbanos.

\begin{abstract}
Social dynamic is inherent in public spaces, which should encourage the encounter and interaction of the users. In addition, it is necessary to have information for the project that exceeds the design preconceptions that the designer usually has. However, it is a challenge to capture the experiences, opinions and activities that users carry out in these spaces. The objective of this article is to propose a methodology for the diagnosis of public spaces that captures the daily dynamics of the population, the perception of the elements that constitute them, as well as the role they play in the neighborhood and in the context of the city. The methodological proposal is framed in a systemic perspective that determines the different dimensions that structure it, the quality criteria and their interrelations, by using different instruments (observation, survey and interview). As a case study, we work in the Plazas El Vergel and El Carbón, located in historic neighborhoods of Cuenca, Ecuador. The obtained result is an integral characterization, as well as a detailed knowledge of the perception of the population and the use of space in a structured way based on theoretical argumentation. With the application of the methodological proposal, we could confirm the importance of the participation of the population in the interventions, resulting in common elements that can be generalized and in turn, in particularities of each space.
\end{abstract}

Keywords: citizen participation, public space, urban perception, urban projects.

Artículo basado en los resultados del Trabajo de Titulación en la Carrera de Arquitectura de la Universidad de Cuenca denominado La percepción de la población como criterio de diseño del espacio público en el Centro Histórico de Cuenca, desarrollado por las autoras.

Documento recibido el 07 de junio de 2019 y aceptado el 17 de diciembre de 2019.

Cómo citar: Muñoz-Vanegas, P., Quizhpe-Marín, M. y Salazar-Guamán, X. (2019). Uso y percepción del espacio público, una mirada desde la población: el caso de Cuenca, Ecuador. Revista de Urbanismo, 41, 1-19. https://doi.org/10.5354/0717$\underline{5051.2019 .53536}$ 


\section{Introducción}

Los espacios públicos son sitios de uso colectivo donde se expresan atributos propios de la dimensión humana, desde su naturaleza física y psicológica. Su configuración es producto tanto de los urbanistas y arquitectos, como de los ciudadanos, quienes son los protagonistas que regulan su uso (Briceño Ávila, 2018). Asimismo, "pueden ser entendidos como objetos materiales que interactúan en procesos sociales subjetivos, ya que a través de esta relación es como adquieren una función, una forma y un significado social" (Córdova y Romo, 2016, p. 15).

Destaca en este sentido su multifuncionalidad, la cual estructura y da sentido a la ciudad, permitiendo el paseo y encuentro entre diversos grupos sociales, donde se intercambian relaciones a través de las cuales se comprende la condición sociocultural de la vida urbana (Ramírez Kuri, 2015), cómo es la ciudad y el nivel de calidad de vida de sus habitantes (Gehl \& Svarre, 2013). Estos espacios otorgan además identidad a las ciudades y enriquecen el paisaje urbano. De esta manera calles, plazas y demás espacios públicos contribuyen a definir las funciones culturales, sociales, económicas y políticas de las ciudades, importantes en el desarrollo de su población; dando origen a diferentes formas de comportamientos, de creación de la memoria ya sea individual o colectiva, a los diferentes usos (Gehl, 2014) y manifestaciones de naturaleza política, cultural, religiosa, entre otras.

Resulta necesario, por tanto, dotarlos de ciertas condiciones físicas y espaciales, que garanticen el uso y disfrute del espacio, faciliten la interacción de los individuos consigo mismos, los demás y el ambiente (Garnica y Vargas, 2017) y establezcan significados en la población. El espacio público se ratifica, así como "un lugar de encuentros y desencuentros que, a través de las múltiples interacciones entre los elementos físicos y sociales, va recreando en la cotidianidad de sus habitantes, una imagen sobre sí mismo" (León, Blanco y Collogo, 2018, p. 44).

No obstante, muchas intervenciones que se llevan a cabo, contrario a su fin, dejan de lado variables de tipo social, ambiental, cultural, que también son componentes de la vida urbana que se produce en estos sitios (Daza, 2018). Es frecuente encontrar diseños en los que, a pesar de los esfuerzos que puedan realizarse, no se logra captar con claridad las experiencias ni opiniones de los usuarios, menos aún las actividades que ellos realizan, producto de la dinámica propia de la plaza, la cotidianeidad de su contexto y su rol particular en la ciudad, centrando su atención básicamente en el aspecto formal.

En este contexto, en el presente artículo se expone una propuesta metodológica para el diagnóstico de los espacios públicos que capte la dinámica cotidiana de la población en ellos, la percepción sobre los elementos que los constituyen, así como el rol que cumplen en el barrio y en el contexto de la ciudad. Para ello se plantean diversas estrategias de análisis orientadas a un entendimiento detallado de su situación actual, a través de una cercana interacción con el área de estudio, entendiendo su funcionamiento y la forma en que los usuarios se relacionan y habitan en él. Se prioriza tanto el manejo de información primaria de fácil acceso que coadyuva a anular ideas preconcebidas acerca de la plaza, como la indagación sobre los puntos de vista de los diversos participantes, sus problemas, perspectivas y argumentos.

Esta propuesta se aplica en las Plazas El Vergel y El Carbón de la ciudad de Cuenca, Ecuador, verificando su pertinencia y operatividad.

\section{Marco conceptual}

En la actualidad la mayoría de los proyectos priorizan lo estético y funcional, que no necesariamente es congruente con la dinámica del espacio a ser intervenido, resultando así, propuestas enmarcadas en preconcepciones de diseño que generalmente tiene el proyectista, las cuales no establecen un correcto equilibrio entre los componentes estético y social, y que resultan, en ocasiones, en diseños esnobistas (García-Doménech, 2015). Indudablemente, el criterio de verdad que maneja quien esboza la propuesta tiene implicaciones decisivas en los partidos que toma al momento de diseñar, se infiere por tanto que su preconcepción es natural en la medida en que ha sido instalada producto de sus experiencias sensoriales y de diseños anteriores (Boeri, 2007). Situación que no debe afectar al espacio público, donde el lenguaje técnico, la racionalidad y la lógica del proyectista se enfrenta permanente a las necesidades cotidianas de los ciudadanos (García-Doménech, 2015).

Muchas de estas actuaciones se ven evidenciadas en ciertas constantes como la poca comprensión social de la abstracción que realiza el proyectista, la falta de diálogo 
entre la historia, los valores y el entorno, es decir, se trata de actuaciones que no reflejan la importancia del contexto histórico donde se emplazan, no toman en cuenta las particularidades de su surgimiento, las transformaciones a lo largo del tiempo y el rol que ha desempeñado en los diferentes momentos históricos de la ciudad, de igual manera se ha relegado los cambios que ha tenido la sociedad y la vertiente cultural de cada lugar. En consecuencia, se generan intervenciones similares unas con otras, carentes de personalidad, que en algunos casos copian o imitan el pasado, creando imágenes superficiales carentes de cultura urbana, afectando de esta forma al imaginario y la memoria colectiva de la población (GarcíaDoménech, 2014).

Como consecuencia, se acentúan problemas como la falta de apropiación y poco uso de estos espacios. Realidad que no es permanente en el tiempo, ya que de manera inevitable muchos espacios no pueden ser prescindidos de la vida cotidiana de la población, llegando incluso a adaptarse a ellos. En un primer momento no hay una apropiación espontánea, empero, los usuarios toman decisiones, emprenden estrategias y desarrollan comportamientos, que matizan su relación con el espacio público, de manera tal que la llevan a un punto positivo.

La población percibe, según la Gestalt, "tan sólo aquella información susceptible de ser agrupada en la conciencia para generar una representación mental" (Oviedo, 2004, p. 90).

De ahí la necesidad de recurrir a estrategias que, con la debida argumentación y rigurosidad, permitan captar tanto las percepciones como las formas de uso de un espacio que refleje la interacción entre usuarios y la plaza. ¿Por qué razón? Porque son ellos y no el arquitecto los que pasarán una parte importante de su tiempo y su vida usando estos espacios (Lotito Catino, 2009), rescatando la importancia del mundo de la percepción.

Se requiere entonces desarrollar y utilizar herramientas que identifiquen con mayor claridad la relación existente entre los usuarios y el espacio público. Si bien no es posible predecir la interacción de dichos usuarios, ciertos estudios pueden brindar una comprensión básica y sugerir soluciones con mayor pertinencia (Gehl \& Svarre, 2013). Es imprescindible identificar cómo el diseño y los equipamientos satisfacen y se adaptan a las necesidades humanas de tipo social, proporcionando las posibilidades de encuentro (Velásquez y Meléndez, 2003), no sólo de quienes viven en un contexto inmediato, sino también de aquella población que, perteneciendo a otros sectores de la ciudad, han hecho parte de sus actividades cotidianas el uso de estos espacios.

El planteamiento aquí propuesto parte de considerar al espacio público como un lugar multifuncional que estructura la ciudad y responde a ciertas dimensiones producto de los usos, formas, funciones y relaciones que se generan en ellos (Garriz y Schroeder, 2014). Constituyen un sitio de encuentro donde los habitantes interactúan y conciben la vida en comunidad. Por esta razón, es necesario dotarlo de ciertas cualidades estéticas, espaciales y formales, que faciliten las relaciones sociales y establezcan significados culturales en la población.

En lo que respecta a las dimensiones del espacio público, autores como Fuentes y Peña (2011) , Díaz (2012), Garriz y Schroeder (2014) y Romero (2016) destacan, entre otras, aquellas de tipo físico espacial, ambiental, social, cultural y de seguridad (Figura 1); por ser las que tienen mayor incidencia en la configuración física de la plaza y están relacionadas con el estudio de la vida pública y el espacio urbano.

De otro lado, existen ciertos criterios que determinan la calidad de vida en las plazas y que son decisivos para el desarrollo de las ciudades y su integración con la población; ya que promueven la vida social de los actores involucrados, el confort visual y físico del espacio y la accesibilidad de acuerdo con su entorno inmediato (Alvarez y Molina, 2017). A partir de autores como PPPS (2010), Gehl (2017) y Rangel (2002), se han seleccionado cinco criterios principales en torno al espacio público, que permiten realizar una evaluación acerca de la calidad de estos sitios: protección, confort e imagen, accesibilidad, identidad cultural y usos y actividades (Figura 1). 


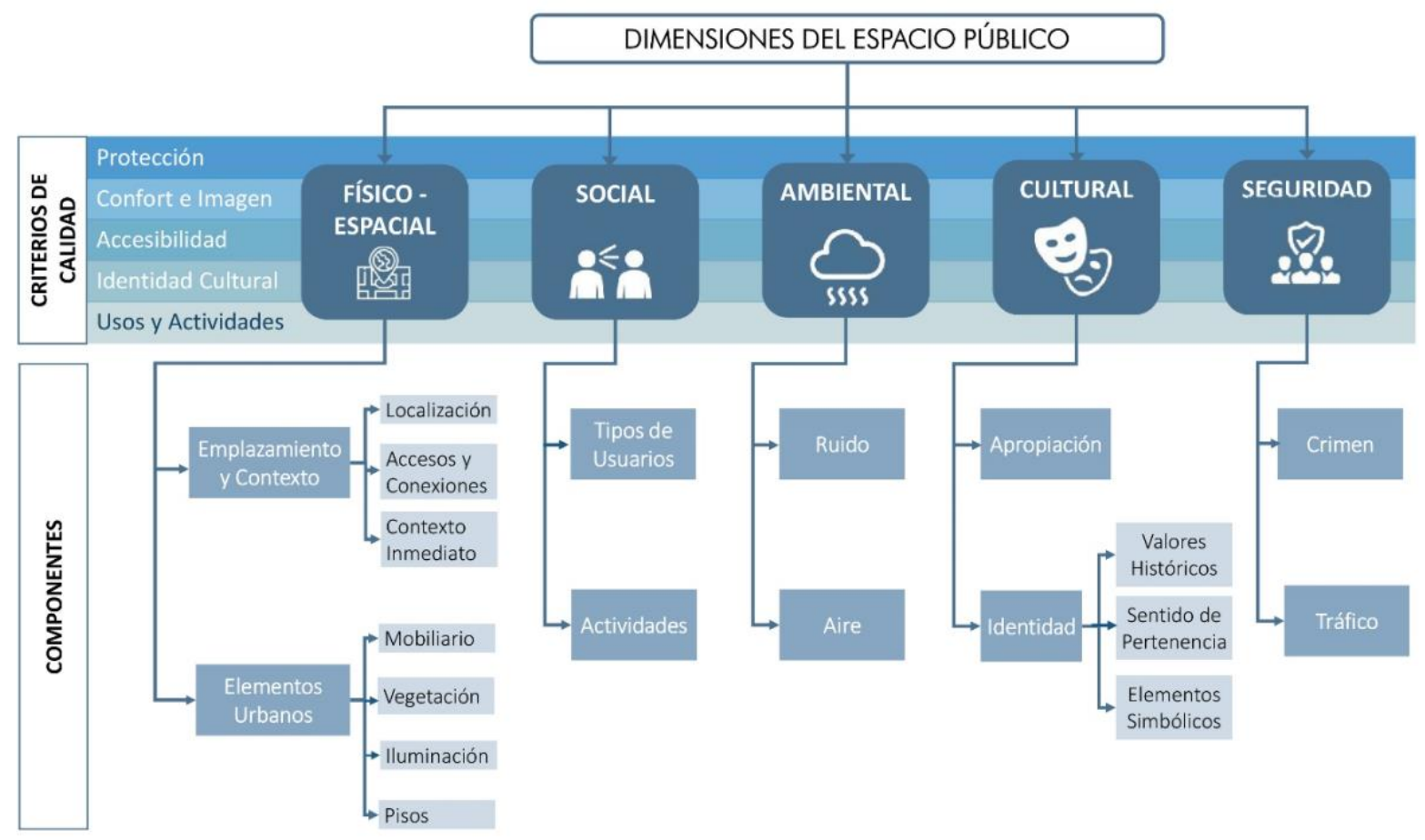

Figura 1. Conceptualización del espacio público: cualidades, dimensiones y componentes. Fuente: Elaboración propia, 2018.

\section{Diseño metodológico}

Una vez identificadas las principales dimensiones de la plaza y sus respectivos componentes, se establece una relación transversal entre cada una de las ellas y los cinco criterios de calidad determinados. Esto permite orientar la propuesta metodológica, ya que establece la conexión entre los elementos (físicos, sociales, culturales) presentes en la plaza y los usuarios, a partir de su nivel de satisfacción en el espacio (Figura 1). La propuesta metodológica pretende ampliar la comprensión y concepción de los espacios públicos de la ciudad, a través de la aplicación de estrategias mixtas de análisis que permitan un diagnóstico completo del área de estudio y deriven en criterios de diseño que beneficien la calidad de vida de los usuarios en estos espacios.

La primera etapa de la propuesta metodológica es una caracterización del área de estudio y se realizó en base a dos de las cinco dimensiones identificadas, la físicoespacial y la cultural. Es una fase de carácter eminentemente descriptiva realizada por el investigador, en el que se capta la dinámica y valores de la plaza a través de la observación directa y aplicación de fichas para relevamiento de características de los elementos urbanos, asi como una revisión bibliográfica de hechos históricos (Figura 2). 


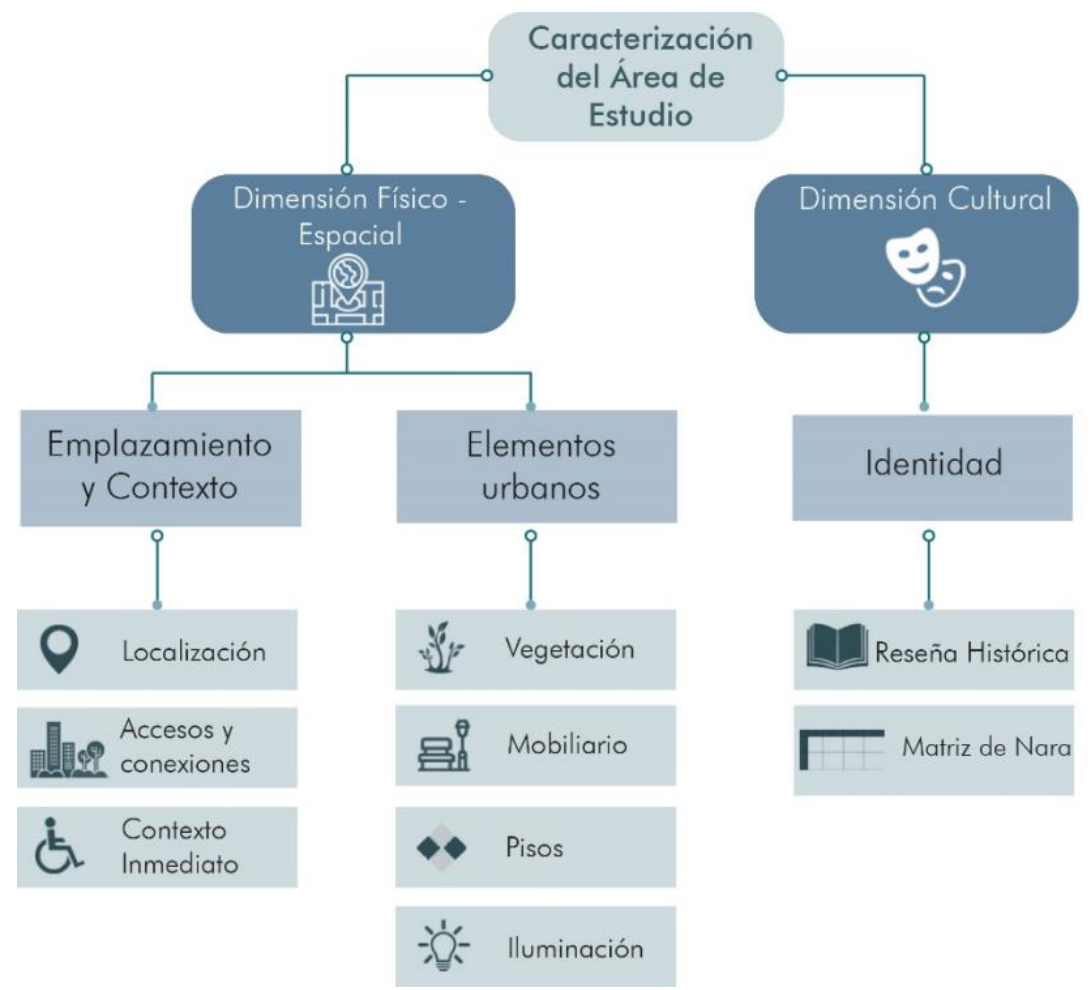

Figura 2. Aspectos por analizar en la caracterización del área de estudio. Fuente: Elaboración propia, 2018.

En una segunda etapa, cobró mayor protagonismo la población, para lo cual se emplearon tres instrumentos que se complementaron entre ellos para el levantamiento de información: observación, encuestas y entrevistas. Se busca alcanzar un análisis integral, en el que, de forma coherente se analicen las dimensiones, los componentes y las cualidades, a partir de variables pertinentes que aporten a captar la dinámica de la plaza y la percepción de distintos tipos de usuarios con mayor detalle ( Figura 3 ). 


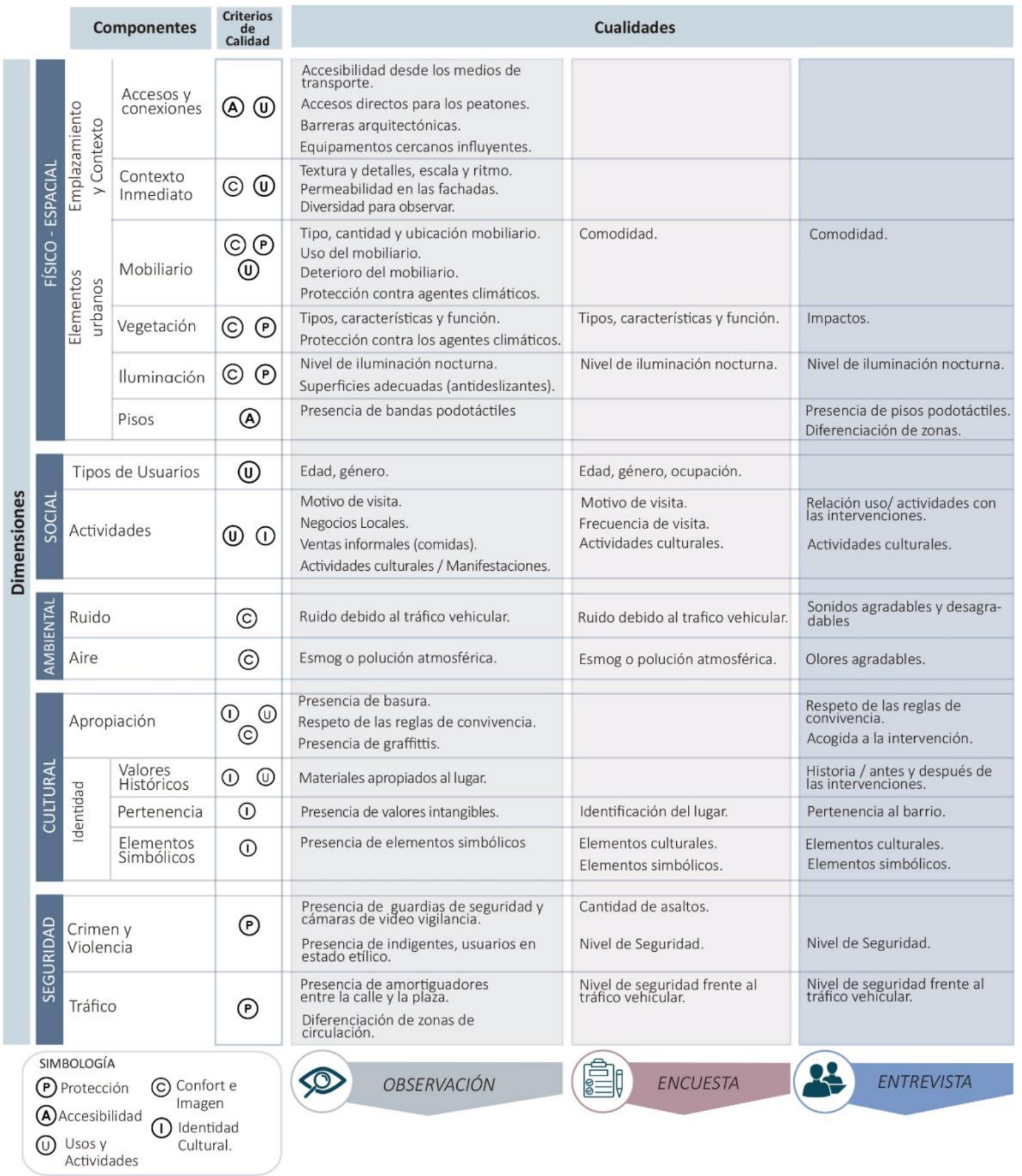

Figura 3. Esquema de aplicación de instrumentos para la caracterización de las dimensiones, componentes y cualidades del espacio público. Fuente: Elaboración propia, 2018

Observación. Como método empírico, permitió al investigador generar un proceso de aprendizaje, a través del involucramiento en distintos grados en las diversas actividades que los participantes realizan en el sitio. A su vez, facultó la indagación de las prácticas que se desarrollan dentro de situaciones cotidianas que debido a su carácter ordinario, no son objeto de atención o reflexión por parte de los mismos individuos (Jociles, 2018). El observador, por tanto, forma parte de los acontecimientos y fenómenos que está observando. Se trata de una conjunción entre percepción e interpretación, donde una adecuada integración sensorial 
facilita una observación correcta. La interpretación originada es resultado de la manera particular y subjetiva del investigador; motivo por el cual la presente metodología hace uso de otros instrumentos para captar distintas opiniones y percepciones que permitan ratificar o su vez, confrontar lo observado respecto de los fenómenos a estudiar.
En la aplicación misma, se definen los periodos del día con mayor confluencia de usuarios en una jornada comprendida entre las 06.00 y 21.00 (Figura 4), franjas horarias en las cuales se emplea el diario de campo y el mapeo de actividades para el levantamiento de información.

\section{El Carbón El El Vergel}

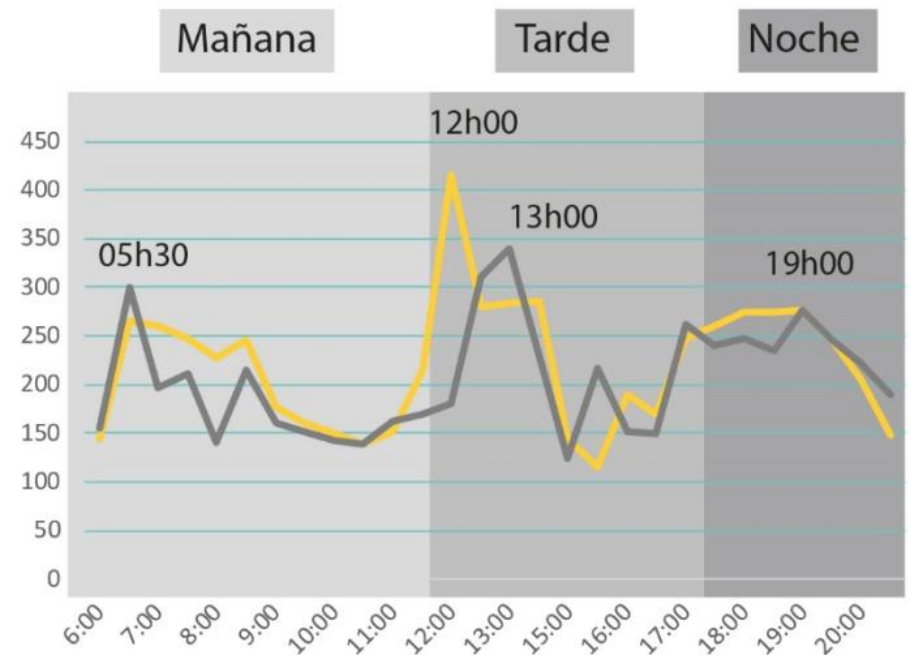

Figura 4. Número de usuarios de la plaza por periodo de tiempo. Fuente: Elaboración propia, 2018.

El diario de campo contiene un registro detallado de los acontecimientos, una descripción de los usuarios y del contexto físico, vivencias y apreciaciones que tiene el observador del medio en el que se encuentra. La ficha consta de hora, descripción e interpretación. Por su parte, el mapeo de actividades proporciona información que permite documentar la cantidad y ubicación de personas que permanecen en la plaza, y las actividades que se encuentran realizando, para lo cual se establecen cuadrantes para localizar los registros levantados (Figura 5). 


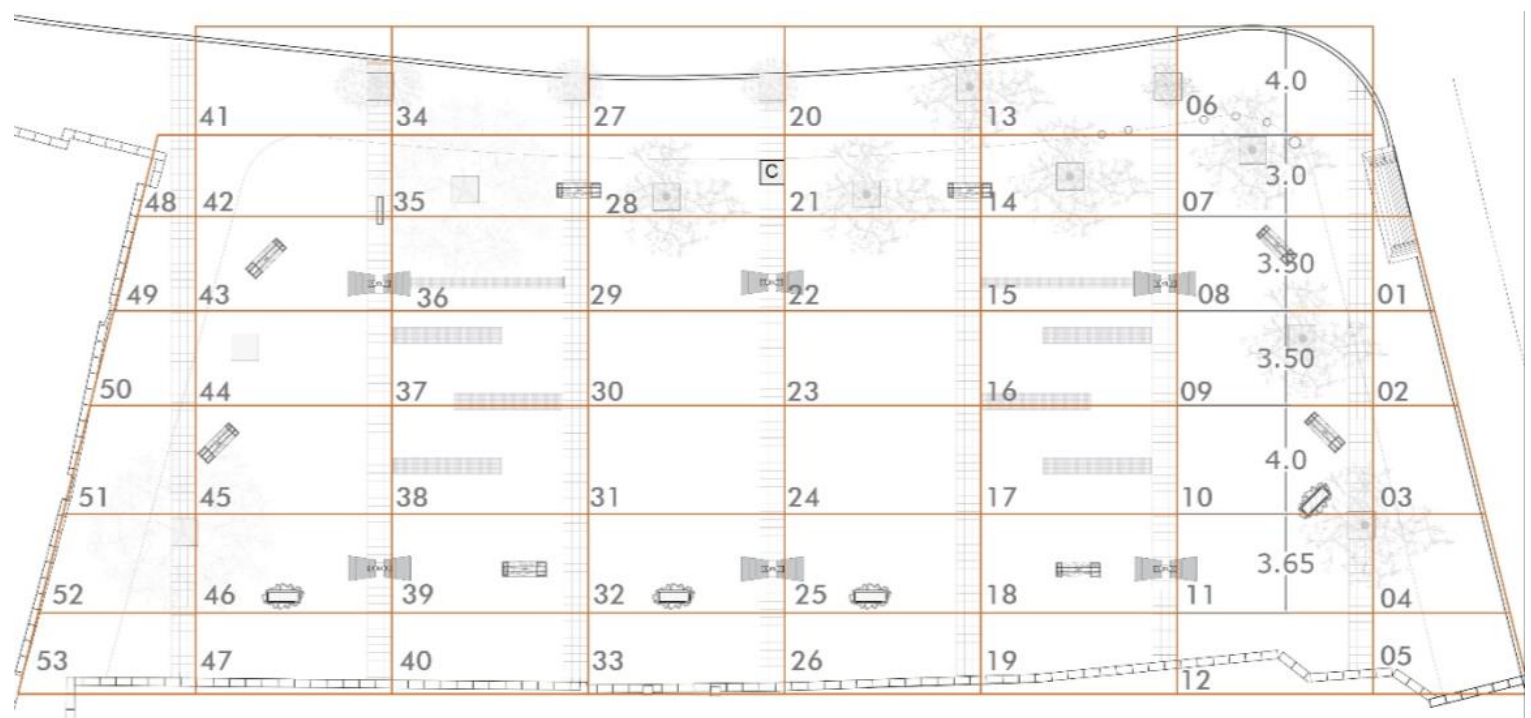

Figura 5. Zonificación por cuadrantes para el mapeo de actividades. Fuente: Elaboración propia, 2018.

Al mismo tiempo, la observación ayudó a determinar los informantes claves, actores representativos o usuarios frecuentes de la plaza, cuya voz tiene mayor representatividad que la de cualquier otro transeúnte.

Encuesta. El objetivo fue encontrar ciertos elementos y factores que generan satisfacción o insatisfacción en los usuarios en relación con protección, confort e imagen, identidad, actividades y percepciones específicas de la población, para lo cual se formuló un cuestionario de 22 preguntas que abordan los criterios antes mencionados.

La población a la cual se aplicó las encuestas es una muestra representativa del total de usuarios determinados en el conteo (población finita), empleándose la siguiente fórmula (Aguilar-Barojas, 2005):

$$
n=\frac{N * Z_{o}^{2} * p * q}{d^{2} *(N-1)+Z_{o}^{2} * p * q}
$$

Donde

$\mathrm{n}=$ población total

Zo=1,96 corresponde al valor del cálculo del área de la curva normal para el nivel de confianza requerido (95\%), contando con un $5 \%$ de error.

$\mathrm{p}=$ es la proporción aproximada en la población de referencia (usar $5 \%=0,05$ )

$q$ = la proporción de la población que no presenta el fenómeno en estudio ( 1 -p). $\mathrm{d}=$ es la precisión absoluta (usar 5\% para investigaciones con un alto grado de confiabilidad).

La muestra se distribuyó proporcionalmente en los periodos de mayor concurrencia en las plazas.

Los resultados obtenidos se cotejan con los datos cualitativos de la caracterización del área de estudio y de la observación, permitiendo así, una serie de interpretaciones y conclusiones que derivan en problemas y potencialidades del lugar.

Entrevista. Se utilizó para complementar información sobre temas relevantes que requieren el testimonio de informantes que tienen mayor representatividad $y$ opinión en el contexto de las plazas. Se trata de actores claves, que fueron determinados durante la observación, personas que, por su particular rol, ayudan a entender las dinámicas que suceden en el espacio desde su experiencia personal, ya sea como observadores de la vida social o actores del espacio vivido.

En esta investigación se aplicó una entrevista semiestructurada, a partir de un guión establecido, en la cual se puede ir introduciendo preguntas que no estuvieron contempladas, con el fin de obtener más información. Este tipo de entrevista es la más usada en investigación cualitativa, pues hay un razonable grado de control por parte del investigador y mayor libertad en las respuestas de los entrevistados (Díaz, Torruco, Martínez y Varela, 2013). 
A través de este instrumento se buscó obtener opiniones de interés desde la visión de los informantes claves, aspectos relacionados con las percepciones generales y las intervenciones realizadas en las plazas, su antes, su después y las transformaciones que han traído consigo. Además, se abordaron preguntas relacionadas con el tema de identidad, por ser un ámbito que requiere la apreciación y conocimiento de personas que han tenido una fuerte relación con el espacio.

Para la selección de los actores claves, se incluyeron miembros de la directiva, adultos mayores, comerciantes del lugar, personas activas de la comunidad y un usuario con discapacidad visual (Figura 6). Es preciso indicar que, las personas no videntes tienen una percepción diferente respecto a la configuración física y funcional de los espacios públicos, cuya opinión debe ser visibilizada para generar una verdadera integración social que contribuya al desarrollo de espacios accesibles e incluyentes.

Con el fin de sistematizar y organizar la información, se formuló una matriz que condensa las entrevistas de los cinco actores claves con base a los componentes de las dimensiones, tras lo cual, se agrupan aquellas opiniones que guardan similitud.

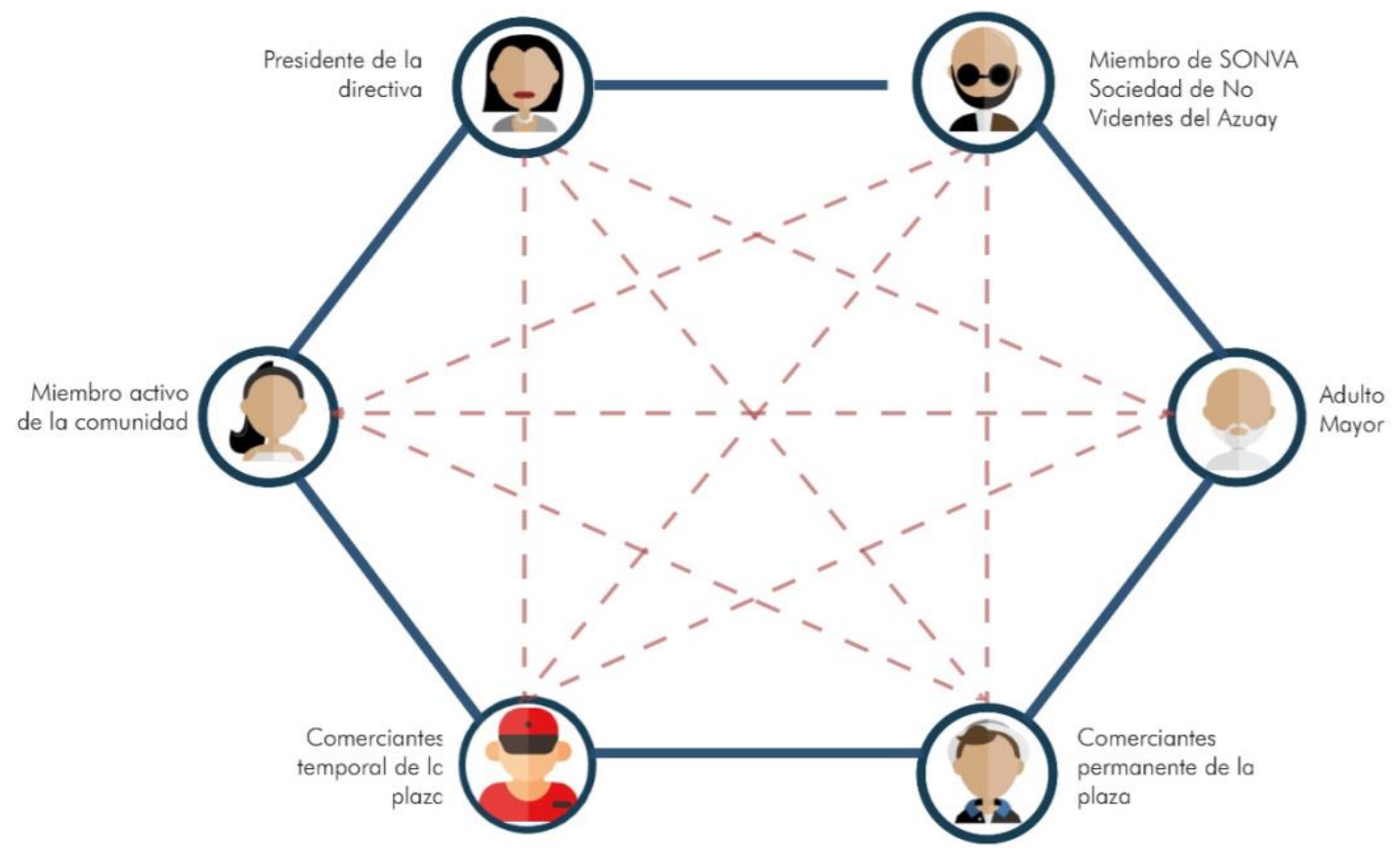

Figura 6. Identificación de actores clave para entrevista. Fuente: Elaboración propia, 2018.

A los resultados obtenidos, se sumaron las conclusiones de los demás instrumentos, y a partir de su integración, se determinaron problemas, potencialidades y formas de uso de cada una de las plazas, lo cual permitió analizar, evaluar y diagnosticar lo que sucede en el espacio con relación a los criterios de calidad.

\section{Casos de estudio}

Las Plazas El Vergel y El Carbón, ubicadas en los barrios tradicionales de El Vergel y San Roque (Figura 7), respectivamente, fueron seleccionadas como casos de estudio al presentar características similares en términos formales y encontrarse localizadas en zonas históricas periféricas del Centro Histórico de Cuenca. Ambas plazas estuvieron enmarcadas dentro del "Plan Especial El Barranco" realizado en el periodo 2004 - 2009, a través de la Fundación El Barranco, el cual planteó la creación y recuperación de los espacios públicos como lugares de concentración y descanso, con el objetivo de proporcionar a los usuarios diversas opciones de recorrido y disfrute de la ciudad (Albornoz, 2004). 


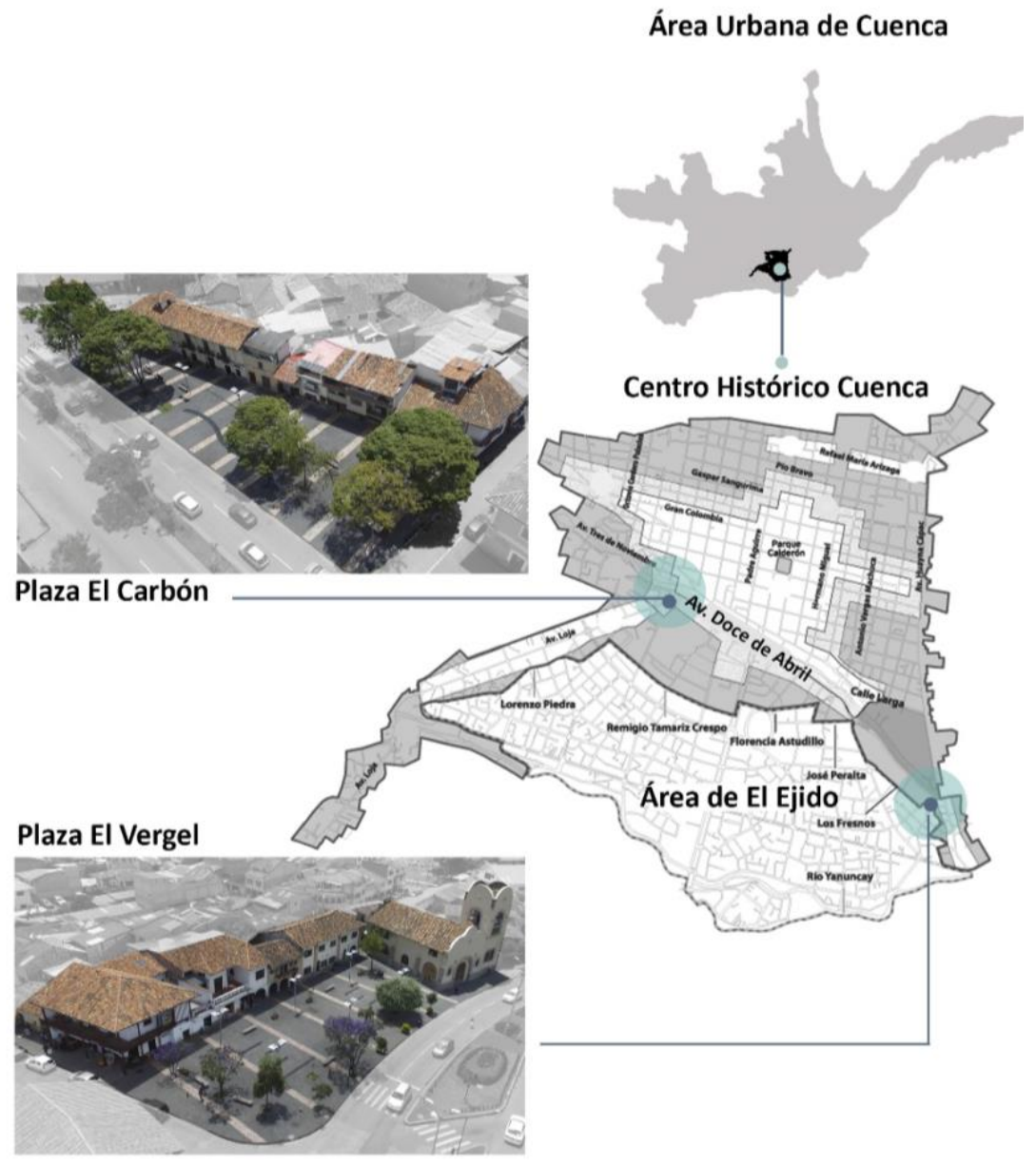

Figura 7. Localización casos de estudio. Fuente: Elaboración propia, 2018.

Las intervenciones que en ellas se realizaron en el periodo mencionado, buscaban la recuperación de las plazas a través de transformaciones físicas que generen mayor accesibilidad y permitan la realización de diversas actividades culturales, así como la integración de estos sitios con su entorno, logrando una correcta apropiación por parte de vecinos y peatones (Albornoz, 2004). Tanto la Plaza de El Vergel como la de El Carbón fueron realizadas por el mismo estudio de arquitectura, y, por lo tanto, presentan la misma línea de diseño.

Los dos barrios poseen un gran patrimonio material e inmaterial, una de las razones por las cuales forman parte del territorio declarado por la UNESCO como Patrimonio Cultural de la Humanidad. Se trata de conjuntos urbanoarquitectónicos de importantes características, donde a más del valor de sus edificaciones, está su riqueza intangible, la cual está presente en su historia, costumbres, tradiciones, leyendas, fiestas religiosas, fiestas populares, gastronomía, características que brindan identidad a estas áreas históricas y reflejan la comunidad barrial que las distingue.

El optar por dos plazas de similares características físico-espaciales permite analizar la utilidad de la propuesta metodológica en contextos diferentes, bajo la premisa de que dichos contextos son condicionantes de la dinámica que se origina en las plazas. A más de ello, es posible emplearla en el análisis de casos particulares, pero también posibilita un estudio comparativo como se verá más adelante. 


\section{Resultados}

Caracterización del área de estudio. Los barrios donde se ubican las plazas constituyen antiguas y tradicionales agrupaciones de la urbe. Las plazas marcan el inicio de calles históricas, ejes viales que concentran gran cantidad de valores tangibles e intangibles, entre los que destacan: la gastronomía local, la arquitectura tradicional y ciertos oficios como el de la forja, en El Vergel.

La cercanía de las plazas a equipamientos educativos y de salud relevantes, entre los que destacan la Universidad de Cuenca y el Hospital Regional Vicente Corral Moscoso, tiene como consecuencia el flujo constante de personas, especialmente jóvenes. Así también, la Sociedad de No Videntes del Azuay (SONVA), ubicada cerca de la Plaza EI Vergel incrementa el número de usuarios con discapacidad visual en el espacio.

Con respecto a la accesibilidad, se determina que las condiciones no son las adecuadas, debido a la presencia de barreras arquitectónicas y a la falta de una adecuada articulación de las rampas y los pasos cebra con su entorno inmediato. Al interior de los sitios, la plataforma única permite tener libre recorrido, beneficiando a la autonomía e inclusión de todos los ciudadanos.

Las Ruinas de Pumapungo en la Plaza El Vergel y el Barranco en la Plaza El Carbón, junto al cordón verde que acompaña al Río Tomebamba, conforman un paisaje abierto y atractivo para observar. Igualmente, las plazas logran una correcta relación con el contexto construido, ya que las edificaciones que rodean el sitio conservan la escala humana y son visibles desde diversos puntos. Sobresalen los inmuebles que presentan detalles en su arquitectura, mayor permeabilidad y locales comerciales, ya que mejoran la experiencia en el lugar.

La textura y el color de la vegetación brindan al espacio armonía visual y contribuyen al bienestar físico y psicológico de las personas. No obstante, la flora de las plazas, en su mayoría, es de color uniforme y los árboles, debido a sus características de follaje o a su ubicación, no brindan la sombra necesaria a las zonas destinadas al descanso.

Por otra parte, las rejillas a nivel de piso que constituyen las fuentes de agua, que se encuentran en desuso, presentan hundimientos, lo cual resulta un peligro para los usuarios que transitan por el lugar. Su falta de uso, al igual que la presencia de un único basurero en el lugar, ha provocado que se acumule basura, aspecto que influye en la imagen del espacio.

El mobiliario no rescata, ni en su diseño, ni en los materiales que lo constituyen, los oficios históricos que representan a los barrios donde se emplazan los sitios, como es la forja en la Plaza El Vergel.

La materialidad del piso colabora con la accesibilidad dentro del espacio, gracias a que está compuesto, en su mayoría por superficies antideslizantes. Los proyectos rescatan al mármol travertino, material de relevancia histórica en la ciudad. Sin embargo, las plazas no cuentan con pisos podo táctiles, cuya función es advertir de un posible peligro y guiar por el camino correcto a personas con discapacidad visual.

Respecto a la iluminación del espacio, la luz emitida por las luminarias no abarca toda la superficie y no consigue alcanzar el promedio de 30 luxes, establecido para plazas por la normativa nacional. No obstante, las lámparas de las edificaciones anexas colaboran con la iluminación del espacio.

Funcionalidad y percepción de la población. Se complementa la caracterización del área de estudio con la aplicación de los tres instrumentos metodológicos para abordar las cinco dimensiones en relación con los cinco criterios de calidad.

Los resultados obtenidos con cada instrumento derivan progresivamente en un análisis acumulativo a través del cual es posible confrontar, ratificar o complementar, según sea el caso, las percepciones de la población.

\section{Observación.}

Protección. Se evidencia la falta de elementos que protejan a los usuarios de los agentes climáticos, principalmente del sol y la lluvia en los diferentes periodos. Se constata la ausencia de personal de seguridad en el espacio, lo cual genera cierto grado de inseguridad, de igual manera, la presencia de personas en estado etílico influye en este grado de percepción.

Por otra parte, no existen áreas de circulación exclusivas para bicicletas, lo cual provoca que estas atraviesen la plaza y se conviertan en un peligro para los peatones que se encuentran en el lugar. 
Confort e Imagen. Se establece la relación e influencia que existe entre los bordes y las actividades que se realizan en la plaza, donde los restaurantes y cafeterías del lugar, son los principales atractivos para la confluencia de personas al sitio. También se destaca la calidad del entorno, los cuales brindan visuales agradables, provocando de esta forma mayor confortabilidad y tiempo de permanencia de las personas.

La localización del mobiliario en las plazas estudiadas, al estar cercano a zonas donde existe alto tráfico vehicular, genera mayor sensación de inseguridad, situación que provoca su poco uso.

Accesibilidad. La plataforma única existente en las plazas facilita la libre circulación de personas con algún tipo de discapacidad. Contrario a ello, se evidencian problemas relacionados con los accesos, su mala articulación con el entorno y la forma de uso del espacio, donde estos no responden a los patrones de uso y movimiento de los peatones. Así también, es notorio que, para las personas con discapacidad visual, no existe una adecuada señalización y diferenciación en la materialidad de los pisos.

Identidad Cultural. Mediante un recorrido se determina que no existen elementos que brinden identidad. Sin embargo, en la etapa de caracterización se identificaron ciertos valores que pudiesen visibilizarse y ser representados en las plazas.

La apropiación del espacio se da a través de la limpieza del sitio, por parte de las empresas municipales y los habitantes del lugar. A pesar de ello, se observa falta de cuidado al mobiliario, grafitis y basura en las jardineras del sitio.

Usos y Actividades. La dinámica de los espacios es diferente tanto en jornadas laborables como en fines de semana. De igual manera, las áreas donde se desarrollan las actividades sociales, opcionales y necesarias son diversas. A pesar de ello, en todos los periodos y días de la semana, es común distinguir la concentración de un alto número de personas en los bordes, donde se encuentran los locales comerciales, y en áreas donde se localiza el mobiliario urbano

Entre semana, por las mañanas se registra mayor porcentaje de actividades necesarias, debido a que los ciudadanos se encuentran de paso hacia sus lugares de trabajo o estudio. Al medio día, prevalecen las actividades sociales y opcionales, ya que los usuarios asisten al sitio para comprar en los locales de los bordes y socializar en el espacio. Por las noches, de igual manera, los restaurantes se constituyen en un atractivo que dinamiza el espacio.

En cambio, durante los fines de semana la plaza tiene un funcionamiento diferente; en el caso de El Vergel la existencia de un equipamiento cercano junto a la plaza influye en el número de actividades, ya que este genera eventos que atrae mayor número de personas e incide en un mayor dinamismo del lugar. En la plaza de El Carbón, contrario a lo que sucede en El Vergel, la plaza se torna desolada, ya que su funcionamiento y uso, se rige principalmente a horarios laborables, donde los usuarios, especialmente estudiantes, acuden al sitio por la parada de bus o a los restaurantes que existen en los bordes.

Encuesta. Las estadísticas muestran que, del total de encuestados, la mayoría son jóvenes, seguidos de adultos, lo cual mantiene congruencia con los datos recopilados en la observación. Con respecto a la ocupación, quienes formaron parte de la encuesta, son, en su mayoría, estudiantes y trabajadores, destacando la relación entre los equipamientos cercanos y la afluencia de personas al sitio. La cantidad de mujeres y varones es similar, permitiendo de esta manera obtener resultados equitativos en cuanto a género.

Protección. En la Plaza El Vergel, el 22\% de usuarios han sido víctimas de una situación de peligro o asalto en la plaza. En el Carbón asciende el porcentaje al 37\%, percepción compartida por mujeres y varones.

En los sitios analizados, más del $58 \%$ de los encuestados opinan que el tráfico vehicular es un riesgo para su estancia en el espacio, lo que guarda concordancia con la relación directa entre las plazas y la calzada. Para finalizar, con respecto al criterio de protección, más del $65 \%$ de personas califican a las plazas como espacios medianamente seguros y seguros.

Confort e imagen. Se pone en manifiesto que, para la mayoría de la población, la vegetación presente en la plaza es escasa.

En relación con el mobiliario urbano, en la Plaza EI Vergel, los datos determinan que, para alrededor de los tres cuartos de la muestra, las bancas son incómodas, no obstante, en la Plaza El Carbón se incrementa la 
percepción de confort, lo que refleja la importancia de incorporar espaldar en el diseño. Con respecto a la iluminación nocturna, la mayoría de los usuarios encuestados, con el $39 \%$, la califican como regular, con lo que se concluye que es pertinente una mejora.

La población, con porcentajes mayores al $80 \%$, distingue al espacio como ruidoso y muy ruidoso debido al tráfico vehicular. A pesar de la incidencia del vehículo, la mayoría de los usuarios no ven la polución atmosférica como un problema que enfrentan las plazas en la actualidad.

Identidad cultural. Se consultó a los usuarios sobre el nombre de las plazas; en El Vergel, el $80 \%$ de las personas encuestadas acertaron, sin embargo, en la Plaza El Carbón, menos del $5 \%$ de la población conoce el nombre del sitio, lo que demuestra la falta de información. El $61 \%$ de los encuestados en El Vergel y el $86 \%$ en El Carbón no identifican un elemento que sobresalga y brinde identidad a la plaza.

Usos y actividades. Las estadísticas corroboran lo detectado a través de la observación al reconocer a las plazas como concurridas debido a su localización y la cercanía con equipamientos relevantes. Así también, califican a las plazas como lugares de paso, donde no existen mayores atractivos. Más del $58 \%$ de usuarios no han presenciado actividades recreativas o culturales en el espacio.

La mayoría de encuestados visitan el sitio todos los días, lo que demuestra que son usuarios frecuentes, dando mayor fiabilidad a la información obtenida.

Percepciones particulares de los usuarios respecto a la plaza. Los usuarios, en su mayoría, exponen la necesidad de incorporar vegetación y fuentes de agua, mayor confort del mobiliario y mejorar los niveles de iluminación. También se nombra el aumento de seguridad en las plazas y la incorporación de atractivos y eventos recreativos.

Para identificar el significado de las plazas para la población, se pidió definirlas en una palabra. En general, las respuestas se orientan a características positivas: bonita, agradable, tranquila, turística, también se relacionan con su historia y emplazamiento. A pesar de ello y en relación con el diseño, varias opiniones coincidieron en que eran espacios comunes, sin algo verdaderamente representativo, catalogándolas como espacios feos, fríos y aburridos.

\section{Entrevista}

Protección. Tanto en la Plaza El Vergel como en la Plaza El Carbón, la mayoría de entrevistados consideran que, junto con la pérdida de gente propia del sector y la llegada de extranjeros, ha incrementado la percepción de inseguridad en el espacio. Así también, confirman la necesidad de control de los sitios por parte de los guardias municipales.

Para un comerciante del sector, existe un problema habitual que enfrentan los distintos espacios públicos de la ciudad: el uso del sitio para el consumo de bebidas alcohólicas y sustancias ilícitas, enfatizando en que son los estudiantes, principalmente, quienes utilizan el espacio de manera inadecuada.

Un factor negativo que se visualizó de manera continua durante la etapa de observación es el ingreso de vehículos a la plaza, en las entrevistas se mencionó que en repetidas ocasiones los automóviles han impactado a los elementos urbanos.

Confort e imagen. Los entrevistados concuerdan con que es necesario el mantenimiento de la flora por parte de las entidades municipales y los habitantes del sector. Así también, destacan la necesidad de incorporar más vegetación en la plaza; se expresa a las plantas como una necesidad actual debido a la polución atmosférica.

Gracias a las entrevistas se evidencia el rechazo de los usuarios hacia las bancas que no presentan espaldar, pues no invitan a la permanencia en el sitio.

Las fuentes de agua requieren de un constante mantenimiento a cargo de las entidades competentes, sin el cual pierden su función y se tornan en elementos negativos. Para los moradores del sector, estas se han convertido en focos de contaminación y en un riesgo latente para los transeúntes.

Los usuarios concuerdan con que sería propicio la incorporación de otros servicios, destacando al internet inalámbrico. En cuanto a la iluminación, las personas coinciden con las mediciones realizadas en la caracterización del área, donde se identificó que la luz emitida por las lámparas no es la adecuada. 
Accesibilidad. El presidente de SONVA, Sociedad de No Videntes del Azuay, compartió sus experiencias y requerimientos acerca del espacio público. Villavicencio alega que los usuarios con discapacidad visual no visitan de manera independiente los espacios debido a su inaccesibilidad; producto del uso de materiales inadecuados, la falta de pisos antideslizantes, bandas podo táctiles, barandas, la presencia de bordos, entre otros. También expresa que las fuentes de agua, debido a la falta de señalización, han sido causantes de anécdotas que han experimentado sus compañeros de la sede.

Identidad Cultural. Los miembros de la comunidad opinan que, a más de la localización estratégica que tiene la Plaza El Vergel, esta constituye la puerta de entrada al barrio. También expresan que, debido a la intervención más reciente, la plaza perdió identidad; comentan que la antigua plaza contenía elementos que eran símbolos de su cultural y formaban parte de su dinámica barrial, los cuales fueron sustituidos por otros que no representan al sitio. Para el presidente de la directiva barrial de El Vergel, la incorporación de elementos tradicionales tiene dos beneficios: colabora con la imagen y representa los valores del barrio.

En varias intervenciones en sitios patrimoniales son los aspectos tangibles los que sobresalen, los intangibles son escasamente considerados y en caso de existir el estudio apropiado no se reflejan en la concreción material de la obra. Para la presidenta de la directiva barrial de San Roque, los espacios han incorporado un modernismo que rompe con todo el romanticismo del patrimonio.

Se determinó que los habitantes presentaron una participación mínima durante las etapas de elaboración y ejecución de los proyectos. La falta de participación de la comunidad tuvo como resultado un proyecto que se alejó de las expectativas, generando la pérdida de apropiación y la falta de cuidado del espacio por los habitantes del barrio y la ciudadanía en general. Asimismo, gracias a las experiencias de los entrevistados, se evidencia que los proyectos no son manejados de manera integral: el diseño no tiene concordancia con las normativas de las diferentes instituciones públicas.

Usos y actividades. Las plazas, en su función de espacios públicos, ejercen diversos roles tanto a nivel de ciudad, como en la comunidad donde se emplazan. Por ello, las intervenciones deberían reflejar equilibrio entre las distintas escalas urbanas, considerando que en el espacio se desarrollan relaciones sociales de la vivencia ciudadana pero también barrial.

Con relación a la Plaza El Vergel, gracias a las entrevistas se evidencia que la plaza ejercía un papel fundamental en la vida comunitaria, la cual se ha desvanecido a partir de la nueva intervención. Con respecto a la Plaza El Carbón, se evidencia como la intervención alteró la dinámica del lugar al modificar los usos cotidianos del sitio, afectando en el confort y la seguridad de los habitantes del sector. Los entrevistados concuerdan con que el beneficio que trajo la intervención ha sido sectorizado, el avance y progreso se ha dado en la zona específica del proyecto.

El diseño y gestión del espacio implica factores que van más allá de la dimensión física, la cual sobresale en los proyectos. Adicionalmente, los atractivos no deben ser únicamente visuales, deben involucrar otros sentidos, como menciona Pallasmaa, caso contrario se evidencia la hegemonía de la vista en el diseño; lo cual ratifica Daniel Villavicencio, persona con discapacidad visual.

Los eventos culturales involucran a la población de otros sectores de la ciudad, sin embargo, para los moradores del sector no tienen mayor relevancia en la dinámica barrial, ya que los problemas que enfrenta la plaza van más allá de las actividades que se desarrollan en el espacio, el cual requiere de un trabajo integral.

\section{Confrontación de los resultados obtenidos a partir de la aplicación de las tres herramientas}

A continuación, se presentan los resultados producto de la integración de las tres herramientas utilizadas, las que priorizan la percepción que tienen los usuarios. En las Figuras 8 y 9 se sintetizan los principales problemas y fortalezas con los que cuenta el espacio público, exponen su situación actual y ponen en evidencia la influencia e importancia que tienen ciertos elementos en el comportamiento de la población y las formas de uso del espacio. 


\begin{tabular}{|c|c|c|c|c|}
\hline & \multicolumn{2}{|r|}{ PLAZA EL VERGEL } & \multicolumn{2}{|r|}{ PLAZA EL CARBÓN } \\
\hline & \multicolumn{4}{|c|}{ CRITERIO DE CALIDAD: PROTECCIÓN } \\
\hline \multirow{3}{*}{ 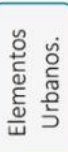 } & \multirow{3}{*}{ () } & $\begin{array}{l}\text { La vegetación ubicada junto a las bancas, por sus } \\
\text { características, no genera sombra. }\end{array}$ & (1) & $\begin{array}{l}\text { La sombra que brinda la vegetación no abarca las } \\
\text { zonas de estancia. }\end{array}$ \\
\hline & & \multicolumn{3}{|c|}{ Existe preferencia de uso hacia el mobiliario que cuenta con protección contra el sol. } \\
\hline & & \multicolumn{3}{|c|}{ No existen elementos que brinden protección contra la lluvia. } \\
\hline \multirow{3}{*}{ 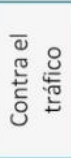 } & (1) & \multirow{2}{*}{\multicolumn{2}{|c|}{$\begin{array}{l}\text { Los arbustos localizados junto a la calzada sirven } \\
\text { como amortiguadores contra el tráfico. } \\
\text { No hay un control del ingreso de los vehículos motorizados. }\end{array}$}} & $\begin{array}{l}\text { Falta de elementos de protección contra el tráfico } \\
\text { vehicular. }\end{array}$ \\
\hline & \$) \& & & & \\
\hline & & \multicolumn{3}{|c|}{ No existen espacios exclusivos para la circulación de bicicletas. } \\
\hline \multirow{4}{*}{ 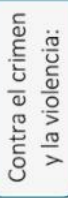 } & 2 & \multicolumn{3}{|c|}{ Mínima presencia de guardias de seguridad. Ausencia de cámaras de video vigilancia. } \\
\hline & & $\begin{array}{l}\text { La alta concurrencia de usuarios aumenta la } \\
\text { sensación de seguridad en el espacio. }\end{array}$ & (1) & $\begin{array}{l}\text { El reducido número de usuariosaumenta la posibilidad } \\
\text { de que se desarrollen situaciones de riesgo. }\end{array}$ \\
\hline & (2) 28 & \multicolumn{3}{|c|}{ La presencia de personas ajenas al barrio genera conflictos } \\
\hline & \& & \multicolumn{3}{|c|}{ La percepción de seguridad varía según la aproximación de los usuarios con el lugar. } \\
\hline \multicolumn{5}{|c|}{ CRITERIO DE CALIDAD: ACCESIBILIDAD } \\
\hline \multirow{4}{*}{ 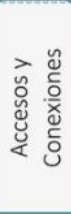 } & () 2 & $\begin{array}{l}\text { Los elementos en el margen de la acera } \\
\text { constituye un obstáculo para los usuarios con } \\
\text { discapacidad visual. }\end{array}$ & & \\
\hline & (1) 2 & \multicolumn{3}{|c|}{ Las rejillas de las fuentes de agua constituyen un obstáculo. } \\
\hline & & \multicolumn{3}{|c|}{ Los accesos no responden a los patrones de uso y movimiento de los individuos. } \\
\hline & $\$$ & \multicolumn{3}{|c|}{ La parada de bus en el sitio o cercana a este garantiza la conectividad del espacio con el resto de la urbe. } \\
\hline \multirow{3}{*}{ 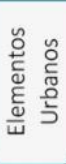 } & \multirow{3}{*}{29} & \multicolumn{3}{|c|}{$\begin{array}{l}\text { La plaza cuenta con una sola plataforma compuesta por superficies antideslizantes que colabora con la accesibilidad al } \\
\text { interior del sitio. }\end{array}$} \\
\hline & & \multicolumn{3}{|c|}{ Las personas con discapacidad no visitan de manera frecuenta el espacio. } \\
\hline & & \multicolumn{3}{|c|}{ Falta de bandas podo táctiles que faciliten la identificación de ciertos elementos del espacio. } \\
\hline \multicolumn{5}{|c|}{ CRITERIO DE CALIDAD: CONFORT E IMAGEN } \\
\hline \multirow{3}{*}{ 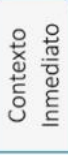 } & () & $\begin{array}{l}\text { Las bancas de la zona norte presentan mejores } \\
\text { visuales. Los arbustos no son un obstáculo. }\end{array}$ & (1) & $\begin{array}{l}\text { El borde sur presenta mayor permeabilidad y mejores } \\
\text { detalles arquitectónicos. }\end{array}$ \\
\hline & () 陣 & \multicolumn{3}{|c|}{ El entorno y las visuales representan un potencial del espacio. } \\
\hline & & La presencia de restaurantes y cafeterías en los bc & ordes genera । & mayor actividad y atracción hacia el sitio. \\
\hline & 淂 & La mayoría de la población califica como regular a & la iluminaciór & n, lo cual implica una posible mejora. \\
\hline 宽 & (1) 2 & Las fachadas, el alumbrado y los eventos externos & s a la plaza col & laboran con la iluminación del espacio. \\
\hline जั & & La luz emitida por las luminarias no es suficiente. & & \\
\hline 苋 & (1) 影 & & 28 & Las bancas con espaldar son consideradas cómodas. \\
\hline$\frac{\bar{\omega}}{\omega}$ & & proporcional al tiempo de permanencia. & () 엑 & $\begin{array}{l}\text { La presencia de desechos de palomas y las manchas } \\
\text { de grafitis no influyen en el confort. }\end{array}$ \\
\hline & & Aspectos Positivos & & Instrumentos \\
\hline & Simbología & Aspectos Negativos & Observación & 28 Entrevista \\
\hline
\end{tabular}

Figura 8. Síntesis de problemas y fortalezas en las plazas dentro de los criterios: Protección, Accesibilidad y Confort e imagen. Fuente: Elaboración propia, 2019. 


\begin{tabular}{|c|c|c|c|c|}
\hline & & PLAZA EL VERGEL & & PLAZA EL CARBÓN \\
\hline & \multicolumn{4}{|c|}{ CRITERIO DE CALIDAD: CONFORT E IMAGEN } \\
\hline \multirow{3}{*}{ 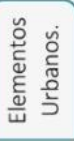 } & \multicolumn{4}{|c|}{ S2 La vegetación es considerada escasa debido a la falta de floración y a la necesidad de más espacios de sombra. } \\
\hline & \multirow{2}{*}{ (9) 2} & \multicolumn{3}{|c|}{ La vegetación no responde a la escala humana, por ende, no es evidente. } \\
\hline & & \multicolumn{3}{|c|}{ No existe un control y mantenimiento de la vegetación por parte de las entidades competentes. } \\
\hline \multirow{2}{*}{$\stackrel{\varrho}{\frac{2}{<}}$} & \multirow{2}{*}{ (1) } & \multicolumn{3}{|c|}{ Las palomas pueden ser consideradas una fuente de contaminación. } \\
\hline & & \multicolumn{3}{|c|}{ La presencia de vegetación y las caracteristicas del espacio colaboran con la calidad ambiental del aire. } \\
\hline$\frac{\circ}{\frac{0}{3}}$ & \multirow[t]{2}{*}{ (9) \& 2} & \multicolumn{3}{|c|}{ No existen sonidos agradables. El tráfico vehicular es la principal fuente de ruido y es una molestia común. } \\
\hline \multicolumn{4}{|c|}{ CRITERIO DE CALIDAD: IDENTIDAD } & \\
\hline \multirow{2}{*}{ 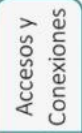 } & (1) 은? & $\begin{array}{l}\text { La plaza se localiza en una zona estratégica, } \\
\text { visible desde varios puntos. }\end{array}$ & & \\
\hline & (1) & \multicolumn{3}{|c|}{ La plaza esta principalmente concurrida por personas que acuden a equipamientos cercanos. } \\
\hline \multirow{2}{*}{$\begin{array}{l}\frac{0}{0} \\
\frac{0}{0} \\
\frac{0}{0} \\
\frac{0}{0} \\
\frac{0}{2} \\
\end{array}$} & 2 & $\begin{array}{l}\text { La intervención generó la pérdida de } \\
\text { apropiación por parte de los habitantes. }\end{array}$ & 2 & $\begin{array}{l}\text { Con la intervención se generaron cambios de uso de } \\
\text { suelo que afectaron a la dinámica barrial. }\end{array}$ \\
\hline & \multirow{2}{*}{ () 造 } & \multicolumn{3}{|c|}{ La falta de apropiación es consecuencia del descuido de los espacios y la carencia de mantenimiento. } \\
\hline \multirow{3}{*}{ 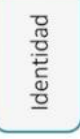 } & & \multicolumn{3}{|c|}{ El entorno es un componente singular que distingue al sitio. } \\
\hline & (1) 2 & \multicolumn{3}{|c|}{ Los valores intangibles del sitio son escasamente considerados, no se reflejan en la concreción material de la obra. } \\
\hline & \multirow[t]{2}{*}{ (1) \& } & \multicolumn{3}{|c|}{ No existe ningún elemento que distinga a la plaza. No se evidencia elementos que brinden identidad a la plaza } \\
\hline & & \multicolumn{3}{|c|}{ CRITERIO DE CALIDAD: USOS Y ACTIVIDADES } \\
\hline 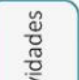 & & $\begin{array}{l}\text { En el fin de semana se evidencia mayor número } \\
\text { de usuarios e interacción social. }\end{array}$ & & $\begin{array}{l}\text { En el fin de semana la concurrencia de usuarios es } \\
\text { menor y el espacio se ve desolado. }\end{array}$ \\
\hline 娄 & () & Sobresalen las actividades sociales. & () & Sobresalen las actividades necesarias. \\
\hline $\begin{array}{l}\frac{1}{0} \\
\frac{0}{0} \\
\frac{0}{0} \\
\frac{0}{2} \\
\end{array}$ & 28 & $\begin{array}{l}\text { Los proyectos no consideran las relaciones } \\
\text { sociales. Tras la intervención, se ha desvanecido } \\
\text { el rol de la plaza en la vida comunitaria. }\end{array}$ & $\$$ & $\begin{array}{l}\text { La intervención no generó un beneficio para todo el } \\
\text { barrio, únicamente a los frentistas. }\end{array}$ \\
\hline 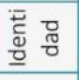 & 2 & $\begin{array}{l}\text { Sobresale la dimensión física respecto a los } \\
\text { ámbitos histórico, cultural o social. }\end{array}$ & 2 & $\begin{array}{l}\text { Históricamente este sitio se ha destacado por ser una } \\
\text { zona de paso hacia sitios importantes. }\end{array}$ \\
\hline 尊 & 2 & $\begin{array}{l}\text { Los principales eventos en la plaza son } \\
\text { organizados por la iglesia y la directiva barrial. }\end{array}$ & (1) & $\begin{array}{l}\text { Se establece una relación entre las características de } \\
\text { las fachadas y el comportamiento de los usuarios. }\end{array}$ \\
\hline & (1) : 내래 & Los equipamientos y locales comerciales de los b & ordes, genera & an mayor actividad y atracción de usuarios. \\
\hline$\subseteq \subseteq$ & & Las actividades en el sitio quedan limitadas al hor & rario y funcio & onalidad de los restaurantes adyacentes a la misma. \\
\hline 岕 & (4) 을 28 & $\begin{array}{l}\text { Las condiciones del espacio son oportunas para } \\
\text { las actividades necesarias, a pesar de no ser } \\
\text { óptimas para que los usuarios permanezcan. }\end{array}$ & (1) & $\begin{array}{l}\text { Las actividades sociales se concentran en áreas donde } \\
\text { el ruido del tráfico es menor y existe protección contra } \\
\text { el sol. }\end{array}$ \\
\hline 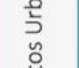 & 28 & $\begin{array}{l}\text { La implementación de internet inalámbrico } \\
\text { colabora con la permanencia de usuarios. }\end{array}$ & (1) \& 8 & $\begin{array}{l}\text { La parada de bus constituye la mayor atracción de } \\
\text { usuarios al sitio y permite la interacción social. }\end{array}$ \\
\hline 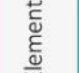 & () & $\begin{array}{l}\text { Los patrones de concentración correspondiente a } \\
\text { ubica el mobiliario, aunque este no cuenta con las }\end{array}$ & $\begin{array}{l}\text { a las actividad } \\
\text { s condiciones }\end{array}$ & $\begin{array}{l}\text { les que se localizan en los bordes y en zonas donde se } \\
\text { necesarias de confort. }\end{array}$ \\
\hline & & $\begin{array}{l}\text { La ubicación lineal de las bancas, repercute en el } \\
\text { algunos de los usuarios han de permanecer de pie }\end{array}$ & $\begin{array}{l}\text { modo de agru } \\
\text { e en búsqued }\end{array}$ & $\begin{array}{l}\text { upación de los usuarios para la conversación, donde } \\
\text { da de contacto visual. }\end{array}$ \\
\hline 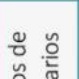 & (1) 2 & $\begin{array}{l}\text { La alta concurrencia de personas provoca la } \\
\text { aglomeración de vendedores ambulantes. }\end{array}$ & & \\
\hline$\stackrel{\circ}{\stackrel{0}{?}}$ & (1) 앱 & $\begin{array}{l}\text { Los usuarios de la plaza, a pesar de estar de paso, } \\
\text { las estadisticas debido a que tienen mayor proxim }\end{array}$ & $\begin{array}{l}\text {, asisten con } f \\
\text { nidad al área }\end{array}$ & $\begin{array}{l}\text { frecuencia al sitio. Lo cual brinda mayor confiabilidad a } \\
\text { de estudio. }\end{array}$ \\
\hline & & Aspectos Positivos & & Instrumentos \\
\hline & Simbología & Aspectos Negativos & Observación & 8 Encuesta \\
\hline
\end{tabular}

Figura 9. Síntesis de problemas y fortalezas en las plazas dentro de los criterios: Confort e imagen, Identidad y Usos y actividades. Fuente: Elaboración propia, 2019. 


\section{Conclusiones}

La relación entre el espacio público y la población que lo habita o usa genera dinamismo y condiciona las actividades que se desarrollan en el sitio. Su contribución en términos de explicitar las características de dicha relación, así como la percepción que tiene sobre el espacio coadyuva en la viabilidad de los proyectos de diseño a ejecutarse, ya que se avanza hacia un entendimiento integral y una conceptualización de como la sociedad percibe, crea y usa el espacio de manera simultánea.

Varias propuestas generadas tienen falencias, debido a que no logran integrarse y no captan las experiencias y opiniones de los usuarios, reduciendo la participación de la población a encuentros con las entidades competentes a través de sucintas exposiciones del proyecto. No obstante, debe entenderse a la población como un elemento clave, en la medida que, vecinos, usuarios de paso, personas que recurren al lugar esporádicamente, todos deben aportar en la creación de espacios de calidad.

Los resultados obtenidos de la aplicación han demostrado que las intervenciones realizadas en las plazas priorizan lo estético, sin responder a la dinámica del espacio y su forma de uso, ya que en su diseño no contemplan los criterios de calidad que responden a las distintas dimensiones (físico - espacial, social, ambiental, cultural y de seguridad) con las que cuentan los sitios. Además, en ocasiones las actuaciones se realizan tomando como referencia proyectos desarrollados en otras locaciones, sin considerar que las condiciones del medio son variables. Por ello, se muestra la necesidad de generar un estudio integral que vincule las dimensiones del espacio y sus componentes con los criterios de calidad para determinar de qué manera el entorno físico influye en la vida urbana y en la calidad de los espacios.

De igual manera, el carácter patrimonial y los valores presentes en estos sitios no se ven reflejados en la concreción formal del diseño de las plazas, lo cual se evidencia a través de la lectura que hacen los usuarios del espacio y sus elementos, misma que no es congruente con la simbolización y abstracción que el proyectista pretendió lograr. Situación que ha reflejado la pérdida de identidad y poca apropiación por parte de sus habitantes.

Por el contrario, se concluye que las plazas que brindan mayor diversidad en sus patrones espaciales, con áreas abiertas y de sombra, con presencia de vegetación, variedad de actividades en el sitio y mayores atractivos, generan mayor y diverso del espacio; ya que acogen a todo tipo de usuarios, personas solas o en grupo, quienes permanecen más tiempo en el sitio debido a que este presenta buenas condiciones que favorecen a una estancia placentera; situación que fortalece las dinámicas sociales y genera arraigo entre los habitantes y la plaza. De manera similar, la inserción de elementos de mobiliario, vegetación e iluminación con características propias del sector contribuye a crear un sentido de apropiación y disfrute de estos lugares, reforzando su identidad, significado y simbolismo.

La formulación de una propuesta metodológica para el estudio de la percepción de los usuarios se fundamenta en un análisis teórico conceptual de aquellas dimensiones, componentes y criterios de calidad que se requiere analizar para el entendimiento exhaustivo de la dinámica de la plaza, dándole a esta fase de diagnóstico pertinencia, estructura y haciendo relevante a la información levantada. Asimismo, cada herramienta permite alimentar un proceso acumulativo en el análisis.

Otro aspecto para tener presente en este caso es la necesidad de ampliar el espectro de criterios de calidad y abordar temas que generalmente son estudiados de manera aislada, con el objetivo de comprender lo que ocurre en las plazas, a partir de determinar el aporte (rol, impacto, influencia) de todos y cada uno de los componentes en dichos criterios.

La combinación de tres instrumentos metodológicos observación, encuesta y entrevista- permite aprovechar los alcances y objetivos específicos de cada uno. Por una parte, la observación facilita el surgimiento de una empatía con el espacio público, rompiendo el esquema tradicional de la investigación según el cual el sujeto se separa drásticamente del objeto de estudio; además, abre la posibilidad de captar situaciones que no pueden ser descritas por los usuarios debido a que forman parte de su cotidianidad y que en la mayoría de los casos se ejecutan de forma inconsciente. Por otra parte, con la encuesta permite obtener, a través de un cuestionario estructurado, opiniones de una muestra representativa de usuarios que utilizan o recorren la plaza, ya sea de manera esporádica o frecuente. Por último, la entrevista al enfocarse en actores claves permite contar con 
información de personas con mayor fuerza discursiva por su rol en el contexto en el que se localiza la plaza.

Finalmente, la aplicación de la propuesta metodológica y los resultados obtenidos muestran su versatilidad para acoplarse a distintas circunstancias tanto respecto del caso de estudio como de los usuarios y actores involucrados, a más de ser factible de emplearse en otras tipologías de espacios públicos [R]

\section{Referencias}

Aguilar-Barojas, S. (2005). Fórmulas para el cálculo de la muestra en investigaciones de la salud. Salud En Tabasco, 11(1-2), 333-338.

Albornoz, B. (2004). Plan Espacial El Barranco. Boris Albornoz Arquitectura. http://www.borisalbornoz.com/proyectos/planespecial-el-barranco/

Alvarez, N., y Molina, L. (2017). Criterios de diseño para el encuentro del edificio y la calle: análisis de las fachadas en planta baja y su influencia en el comportamiento de los peatones en la Av. Remigio Crespo [Tesis de Pregrado]. Universidad de Cuenca, Facultad de Arquitectura y Urbanismo.

Boeri, M. (2007). Apariencia y realidad en el pensamiento griego: Investigaciones sobre aspectos epistemológicos, éticos y de teoría de la acción en algunas teorías de la Antigüedad. Buenos Aires: Colihue.

Briceño Ávila, M. (2018). Paisaje urbano y espacio público como expresión de la vida cotidiana. Revista de Arquitectura, 20(2), 10-19. http://dx.doi.org/10.14718/revarq.2018.20.2.1562

Colmenares, M., y Padilla, P. (2018). Reseña Bibliográfica: Espacio urbano y actores sociales en la Ciudad de Chihuahua: ¿Mutua reconfiguración? Frontera Norte, 30(59), 193-196.

Córdova, G., y Romo, M. (2016). Espacio urbano y actores sociales en la Ciudad de Chihuahua: ¿Mutua reconfiguración? Tijuana, México: El Colegio de la Frontera Norte.

Daza, W. J. (2018). La intervención en el Espacio Público como estrategia para el mejoramiento de la calidad de vida urbana. Caso de Estudio: Valle de Laboyos (Pitalito- Huila) [Tesis]. Maestría en Planeación Urbana y Regional, Pontificia Universidad Javeriana. Recuperado de: https://www.javeriana.edu.co/biblos/tesis/arquitectu ra/tesis23.pdf
Díaz, A. (2012). La visión multidimensional del espacio público en la gestión del desarrollo urbano sustentable de Ensenada, B.C.: Análisis y conceptualización [Tesis de Postgrado]. El Colegio de la Frontera Norte, Tijuana. Recuperado de: https://www.colef.mx/posgrado/wpcontent/uploads/2014/03/TESIS-Diaz-HoeflichArmando-MDR.pdf

Díaz, L., Torruco, U., Martínez, M. y Varela, M. (2013). La entrevista, recurso flexible y dinámico. Investigación en educación médica, 2(7), 162-167. Recuperado de: http://www.scielo.org.mx/scielo.php?script=sci artte xt\&pid=S2007-50572013000300009\&lng=es\&tlng=es

Fuentes, C. y Peña, S. (2011). Espacio público y género en Ciudad Juárez, Chihuahua. Accesibilidad, sociabilidad, participación y seguridad. Juárez, México: El Colegio de la Frontera Norte.

García-Doménech, S. (2014). Percepción social y estética del espacio público urbano en la sociedad contemporánea. Arte, Individuo y Sociedad, 26(2), 301-315. http://dx.doi.org/10.5209/rev ARIS.2014.v26.n2.416 $\underline{96}$

García-Doménech, S. (2015). Estética e interacción social en la identidad del espacio público. Arte y Ciudad: Revista de Investigación, (7), 195-212. http://dx.doi.org/10.22530/ayc.2015.N7.252

Garnica, R. y Vargas, M. (2017). El espacio público en la Comuna 7 de la ciudad de Montería (Colombia) a partir de elementos físico-espaciales y sociales de sus usuarios. Estudios Socioterritoriales, 22. Recuperado de:

http://www.scielo.org.ar/scielo.php?script=sci_arttex t\&pid=S1853-43922017000200010\&Ing=es\&tlng=es.

Garriz, E. y Schroeder, R. (2014). Dimensiones del espacio público y su importancia en el ámbito urbano. Revista Científica Guillermo de Ockham, 12(2). Recuperado de: http://www.redalyc.org/html/1053/105338606003/ 
Gehl Institute. (2017). Twelve Quality Criteria. Gehl Institute. Recuperado de: https://gehlinstitute.org/wpcontent/uploads/2017/08/QUALITY-CRITERIAFINAL.pdf

Gehl, J. (2014). Ciudades para la gente. Buenos Aires, Argentina: Ediciones Infinito.

Gehl, J., \& Svarre, B. (2013). How to study public life. Washington: Island Press.

Jociles, M. (2018). La observación participante en el estudio etnográfico de las prácticas sociales. Revista Colombiana de Antropología, 54(1), 121-150. https://dx.doi.org/10.22380/2539472x.386

León, L., Blanco, R. y Collogo, K. (2018). Significación del espacio barrial como imagen de ciudad: el caso de Pescaíto, Santa Marta. Andamios, 15(38), 39-64. https://dx.doi.org/10.29092/uacm.v15i38.651

Lotito Catino, F. (2009). Arquitectura Psicología Espacio E Individuo. AUS, (6), 12-17. http://dx.doi.org/10.4206/aus.2009.n6-03

Oviedo, G. (2004). La definición del concepto de percepción en psicología con base en la teoría Gestalt. Revista de Estudios Sociales, (18), 89-96. Recuperado de: http://www.scielo.org.co/pdf/res/n18/n18a10.pdf
PPS. (2010). What makes a successful place? - project for public spaces. Recuperado de: https://www.pps.org/article/grplacefeat

Ramírez Kuri, P. (2015). Espacio público, ¿espacio de todos? Reflexiones desde la ciudad de México. Revista mexicana de sociología, 77(1), 07-36. Recuperado de: http://www.scielo.org.mx/scielo.php?script=sci_artte xt\&pid=S0188-25032015000100001\&lng=es\&tlng=es.

Rangel, M. (2002). Los cien... del espacio público para la vida sociocultural urbana. Mérida. Recuperado de: http://www.saber.ula.ve/bitstream/123456789/3979 7/1/Rangel 2002.pdf

Romero, C. (2016). Espacios Públicos Y Calidad De Vida Urbana. Estudio de Caso en Tijuana, Baja California [Tesis de Postgrado]. El Colegio de la Frontera Norte. Recuperado de: https://www.colef.mx/posgrado/wpcontent/uploads/2016/12/TESIS-Romero-ChávezChristian-Rodrigo.pdf

Velásquez, C. y Meléndez, L. (2003). La morfología y los usos de las plazas urbanas y parroquiales de la ciudad de Maracaibo. Opción, 19(40), 69-87. Recuperado de: http://www.scielo.org.ve/scielo.php?script=sci arttex $\underline{\text { t\&pid=S1012-15872003000100005\&lng=es\&tlng=es }}$ 